REVIEWS

\title{
Telemedicine: New horizons in healthcare
}

\author{
Amir Radfar ${ }^{1}$, Carol Lynn Chevalier ${ }^{2}$, Nicole Rouse ${ }^{3}$, Diana Patriche ${ }^{4}$, Irina Filip*5 \\ ${ }^{1}$ College of Graduate Health Studies, A. T. Still University, Mesa, Arizona, United States \\ ${ }^{2}$ Department of Interdisciplinary Health Sciences, A. T. Still University, Arizona, United States \\ ${ }^{3}$ Western University of Health Sciences, Pomona, California, United States \\ ${ }^{4}$ Psychiatry, Policlinic Polimed Apaca, Bucharest, Romania \\ ${ }^{5}$ Psychiatry Residency Program, Kaiser Permanente Fontana, Southern California, United States
}

Received: November 27, 2016

DOI: $10.5430 /$ jha.v6n2p40
Accepted: February 15, 2017

Online Published: February 28, 2017

\begin{abstract}
Objective: Telemedicine allows physicians to provide medical care remotely through audiovisual technology. Telemedicine may address many challenges facing our society: an aging population, chronic disease management, and healthcare cost. With this work, we attempt to evaluate how telemedicine can effect a change in these challenges, and evaluate what obstacles prevent some providers from using it.

Methods: In this work, the cost-effectiveness, success of telemedicine care, usefulness in reaching developing and underdeveloped areas, difficulties preventing the use of telemedicine, and proposals to overcome these challenges were reviewed and analyzed. Results: Cost of telemedicine was reported 19\% less expensive than traditional face-to-face care. In several studies, telemedicine was documented to have had equal or better outcomes for obstructive sleep apnea, geriatrics, heart failure, preventative medicine, and patient compliance. Difficulties in using telemedicine include affordability of equipment, lack of technical support in developing or underdeveloped areas, legality of licensure and patient privacy and satisfaction.

Conclusions: Although cost savings and convenience are major advantages of this technology, concerns with delivery barriers and challenges require cautious embracement of telemedicine. A great deal of research is needed to show that telemedicine improves patient centered outcomes.
\end{abstract}

Key Words: Telemedicine, Affordability of medical services, Rural medicine, Patient satisfaction, Licensing, Privileging

\section{INTRODUCTION}

Telemedicine is the use of medical information, exchanged from one site to another through electronic communication channels, for patients' and health care providers' medical and educational need. ${ }^{[1]}$ The purpose of telemedicine is to make patient care more accessible. Teleradiology and telepathology are examples of telemedicine in which images are captured and sent to different locations for further evaluation. New technological advances, including high-resolution video cameras and broadband internet, have brought remote and real-time patient care to a different level. In 2012, half of the
United States hospitals reported having active telemedicine programs, indicating that telemedicine is now a mainstream treatment modality. ${ }^{[2]}$ Telemedicine continues to develop through new evolving technologies, new services, and new approaches. With this work, we attempt to evaluate the potential impact of telemedicine, and discuss obstacles that prevent some providers from using it.

\section{EFFECTIVENESS OF TELEMEDICINE}

Reviewed research data supports the cost effectiveness of telemedicine services. It saves patients, providers, and pay-

*Correspondence: Irina Filip; Email: irina.filip@kp.org; Address: 17234 Valley Blvd, Fontana, CA. 92335, United States. 
ers' money when compared with traditional methods of health care delivery. In a study by Cryer Shannon, Van Amsterdam and Leff, cost for telemedicine was $19 \%$ lower with equal or better outcomes compared with similar inpatient treatments. ${ }^{[3]}$ In 2016, the United States government has begun coverage of telemedicine through Medicaid and Medicare health plans. ${ }^{4]}$ Many other health plans have implemented telemedicine coverage with intentions to lower costs and even generate revenue. The American Telemedicine Association released its research outcomes on the impact of telemedicine on healthcare cost and quality, which reported cost savings for health care payers, providers, and patients. ${ }^{[1]}$

In addition to being cost-effective, telemedicine provides health care efficiently and effectively. In a multi-center randomized clinical trial for sleep apnea management, Isetta et al. reported that telemedicine was as effective as the traditional face-to-face approach in obstructive sleep apnea (OSA) management. ${ }^{[5]}$ In another study, Shah et al. reported that high-intensity telemedicine reduced the number of emergency department visits, and expanded access for all senior citizens living in a community residence for ambulatory care. ${ }^{[6]}$ Flodgren et al. found that the use of telemedicine in the management of heart failure cases had outcomes comparable to the traditional face-to-face approach. ${ }^{[7]}$ They also reported that telemedicine could improve blood glucose control in those with diabetes. ${ }^{[7]}$ Willis Towers Watson surveyed several employers and reported that because of the convenience and efficiency of telemedicine, it has been implemented in their employee's benefits. ${ }^{[8]}$ The effectiveness of telemedicine is ultimately related to the health care provider, the healthcare system involved, the patient population, and the disease course.

\section{IMPROVING ACCESS TO HEALTHCARE}

Telemedicine is an opportunity to improve access to healthcare in remote and rural areas, where access to healthcare is limited. Increasing the accessibility of specialized medical professionals in these remote areas will allow patients to seek early consultation, be more compliant with treatment, keep vaccinations up to date, and improve their quality of life. ${ }^{[9]}$ Extending telemedicine to rural areas will facilitate and motivate clinicians to treat these hard-to-reach patients. Implementation of telemedicine facilitates better communication between remote areas and offers opportunities for remote education and training. ${ }^{[9]}$ Telemedicine allows physicians to collect data from these remote populations, and allows epidemiologists to obtain stronger public health data on different health issues. This gives the opportunity for planning vaccinations and facilitates potential follow-ups. More efforts should be undertaken at the national and inter- national level by funding telemedicine technology. Increase in telecommunication access in remote or rural areas, highspeed bandwidth, and digital storage allow telemedicine to be an effective solution in low-resource settings, and eventually will assist a better management of limited medical resources. Despite its many benefits, telemedicine faces many obstacles that prevent its implementation into health care policies worldwide.

\section{Challenges of telemedicine}

Due to several challenges, telemedicine has yet to become a worldwide resource. As of yet, many countries do not include telemedicine in their health care policies or regulations as a solution to health problems; therefore, there are no regulatory laws to support telemedicine. In many countries, there is a lack of knowledge of the applications of telemedicine. ${ }^{[9]}$ In the United States, use of telemedicine requires licensing and privileging for health care practitioners. As such, it is required for a healthcare provider to be licensed in the state where the practitioner is working, and may require licensure in the state where the patient is located. ${ }^{[10]}$ To ease the licensure requirements, some state medical boards issue temporary licensees or special telehealth licenses. Some other states instituted exceptions including physician to physician consultation only, specific rules for bordering states and military personnel, and provision of telehealth services in case of natural disasters. ${ }^{[11]}$ A potential solution to these complicated licensure issues would be the implementation of federal laws or creation of an interstate medical licensure to expedite the licensure process in multiple states. ${ }^{[11]}$

Prescribing medications through telehealth is also challenging, as it is influenced by state and federal laws. The Ryan Haight Online Pharmacy Consumer Protection Act, signed into law in 2008, allows physicians to prescribe controlled substances over the Internet if a therapeutic patient-provider relationship has been established. ${ }^{[12]}$ Another issue involves the legality of patient privacy, transfer, and storage of patient information, and authentication of patients and healthcare providers. ${ }^{[9]}$ Medical liability requires regulation in order to protect all parties involved. In a 2010 World Health Organization (WHO) report, researchers found that cultural differences and language barriers might also interfere with the telemedicine, by lacking the culture of sharing the skills and knowledge remotely. ${ }^{[9]}$

\section{OPPORTUNITIES IN TELEMEDICINE}

Telemedicine is set to meet unmet medical needs. However, the degree of patient satisfaction receiving care through telemedicine may vary depending on specialty. The feeling of receiving personalized care from a health care provider, 
who is concerned with the patient's problems, brings satisfaction for most patients. In addition, results from the providers' point of view generally are quite positive due to increase in health care quality offered by telemedicine technology, convenience, and accuracy of the diagnosis. ${ }^{[13]}$ Establishing a good alliance between the treating provider and the patient is conducive to improved treatment outcomes and engagement in treatment. However, some data shows concerns on building a patient-physician relationship remotely via Internet. ${ }^{[14]}$ Affordability, lack of technical expertise support for telemedicine system, under-developed infrastructure, and competing priorities within the health care system are among other barriers playing a negative role in the implementation of telemedicine services. ${ }^{[9]}$

The United States has implemented regulations to support and regulate the use of telemedicine; in order for a healthcare provider to partake in telemedicine, there is a specific credentialing process in place. ${ }^{[15]}$ Longitudinal care through telemedicine is a key component of its use, and it is important to assess the receiving facility's ability to safely carry out continued medical services. Despite these challenges, telemedicine has several benefits to providing worldwide, accessible, and effective healthcare.

Actions to resolve these challenges may allow wide utilization of telehealth care, and may thereby improve healthcare accessibility and efficiency. Legislation and policies are essential to prevent risk of violating patient privacy, to prevent fraud, and to provide healthcare ethically. ${ }^{[9]}$ In the United States, one useful approach to decrease the burden for providers at the originating site is to regulate licensure and credentialing at a national level. ${ }^{[16]}$ This would allow providers to deliver healthcare to any state with one license, opposed to receiving a license for each state to which they deliver healthcare. States that did not require special licensure to practice telemedicine, and instead required private-payer reimbursement, were much more likely to implement tele- care. By relaxing these policies, telemedicine may become more accessible.

Providing adequate training for personnel at both the originating and receiving sites may reduce risk of morbidity and mortality when faced with technological malfunctions. The Affordable Care Act may also play a role in making telecare more valuable, as it penalizes readmissions that occur within thirty days of discharge, and provides incentives for keeping patients healthy through better communicative care. ${ }^{[16]}$ Telemedicine allows for efficient medical care that can prevent hospital readmission, and allows for easy communication between a patient and health maintenance.

\section{Conclusions}

Telemedicine is the provision of medical care remotely through audiovisual technology. Telemedicine is changing the relationship between physician and patient and can address many challenges facing our society, such as aging population, chronic patient management, and healthcare cost deduction. Because patient satisfaction plays a pivotal role, more education is needed to increase patients' awareness of telecare services, and more research is needed to compare the quality of service offered through telemedicine and the traditional face-to-face method. Cost savings and convenience are major advantages of this technology, but barriers involving legality, cultural and language barriers, and technological difficulties continue to prevent the implementation of telecare. A great deal of research is needed to demonstrate that telemedicine improves patient centered outcomes.

\section{ACKNOWLEDGEMENTS}

The authors would like to thank A. T. Still University of Health Sciences for assistance with this manuscript.

\section{CONFLICTS OF INTEREST DisClOSURE}

The authors declare they have no conflict of interest.

\section{REFERENCES}

[1] American Telemedicine Association. Telemedicine's impact on healthcare cost and quality. 2015. Available from: http://www.americantelemed.org/docs/default-source/ policy/examples-of-research-outcomes---telemedicin e's-impact-on-healthcare-cost-and-quality.pdf

[2] Kahn JM. Virtual visits - Confronting the challenges of telemedicine. N Engl J Med. 2015; 372(18): 1684-1685.

[3] Cryer L, Shannon SB, Van Amsterdam M, et al. Costs for 'hospital at home' patients were 19 percent lower, with equal or better outcomes compared to similar inpatients. Health Aff. 2012; 31(6): 1237-1243. https://doi.org/10.1377/hlthaff.2011.1132
[4] Lacktman N. Five telemedicine trends transforming health care in 2016. 2015. Available from: https: //www.linkedin.com/pulse/five-telemedicine-tre nds-transforming-health-care-2016-lacktman

[5] Isetta V, León C, Embid C, et al. Telemedicine-based strategy for sleep apnea management: A multicenter randomized controlled trial. Eur Respir J. 2014; 44(58): 2020. Available from: http://erj .er sjournals.com/content/44/Suppl_58/P2020. shortHh

[6] Shah MN, Wasserman EB, Wang H, et al. High-intensity telemedicine decreases emergency department use by senior living community residents. J Am Med Dir Assoc. 2015.

[7] Flodgren G, Rachas A, Farmer AJ, et al. Interactive telemedicine: 
Effects on professional practice and health care outcomes. Cochrane Database Syst Rev. 2015.

[8] Willis Towers Watson. Employers plan to expand of onsite health centers. 2015. Available from: https: //www.towerswatson.com/en/Press/2015/05/employ ers-plan-to-expand-use-of-onsite-health-Hh

[9] World Health Organization (WHO). Telemedicine: Opportunities and developments in member states: Report on the second global survey on eHealth. 2010. Available from: http://www. who.int/ goe/publications/goe_telemedicine_2010.pdfHh

[10] U.S. Department of Health and Human Services. Are there state licensing issues related to telehealth? 2013. Available from: http://www.hrsa.gov/healthit/toolbox/RuralHea lthITtoolbox/Telehealth/aretherelicensingHh

[11] Resource Centers. Cross-state licensure. 2016. Available from: http://www.telehealthresourcecenter.org/toolbox-m odule/cross-state-licensure

[12] Telehealth Resource Centers. Telehealth and prescribing. 2016. Available from: http: //www.telehealthresourcecenter.org /toolbox-module/telehealth-and-prescribing

[13] Hilty DM, Ferrer DC, Parish MB, et al. The effectiveness of telemental health: a 2013 review. Telemedicine and e-Health. 2013; 19(6): 444-454. https://doi.org/10.1089/tmj.2013.0075

[14] Hanna GM, Fishman I, Edwards DA, et al. Development and patient satisfaction of a new telemedicine service for pain management at Massachusetts General Hospital to the Island of Martha's Vineyard. Pain Med. 2016; 17(9): 1658-63. https://doi.org/10.1093/pm /pnw069

[15] Department of Veterans Affairs. U.S. Department of Veterans Affairs Credentialing and Privileging: A patient safety issue. 2015. Available from: https://veterans.house.gov/hearing-transcript/ us-department-of-veterans-affairs-credentialing-a nd-privileging-a-patient-safety

[16] Adler-Milstein J, Kvedar J, Bates DW. Telehealth among US hospitals: Several factors, including state reimbursement and licensure policies, influence adoption. Health Aff. 2014; 33(2): 207-215. https ://doi.org/10.1377/hlthaff . 2013.1054 